\title{
CORRIGENDUM
}

\section{Phosphodiesterase type 5 inhibitors' extended duration of response as a variable in the treatment of erectile dysfunction}

ME Dunn, SE Althof and MA Perelman

International Journal of Impotence Research (2007) 19, 228. doi:10.1038/sj.ijir.3901505

Correction to: International Journal of Impotence Research (2007) 19, 119-123. doi:10.1038/sj.ijir. 3901490

Following the publication of this article, it was discovered that the affiliations for Drs Althof and Perelman were incorrectly listed.
For Dr Perelman, the correct affiliation is 'Psychiatry, Reproductive Medicine and Urology, New York Presbyterian Hospital/Weill Cornell Medical Center, New York, NY, USA'.

For Dr Althof, the correct affiliation is 'Case Western Reserve University School of Medicine, Cleveland, $\mathrm{OH}$, USA and Center for Marital and Sexual Health of South Florida, West Palm Beach, FL, USA'. 